\title{
Understanding Animal Companion Surplus in the United States: Relinquishment of Nonadoptables to Animal Shelters for Euthanasia
}

\author{
Philip H. Kass \\ School of Veterinary Medicine \\ University of California \\ John C. New, Jr. \\ College of Veterinary Medicine \\ University of Tennessee \\ Janet M. Scarlett \\ College of Veterinary Medicine \\ Cornell University \\ Mo D. Salman \\ College of Veterinary Medicine and Biomedical Sciences \\ Colorado State University
}

\begin{abstract}
Relinquishing a nonhuman animal to a shelter is a complex decision that, it is often believed, ultimately may represent a breakdown of the human-animal bond. The result of such a breakdown is an animal companion surplus in the United States, which is no better evidenced than by the statistics documenting the millions of animals euthanized at shelters every year. This research examined the companion animals who are relinquished by their owners to shelters for adoption and compared them specifically to those relinquished for euthanasia. The study also compared the owner characteristics of the animals in these two groups. Although the majority of dogs and cats relinquished are clearly adoptable, a sizable number of these pets presented to shelters for euthanasia have problems precluding their adoptability: old age, illness, and refractory behavior.
\end{abstract}

Requests for reprints should be sent to Philip Kass, Department of Population Health and Reproduction, School of Veterinary Medicine, University of California, Davis, CA 95616. 
In the public's eye, the most obvious manifestation of companion animal surplus in the United States is the magnitude of the numbers of dogs and cats euthanized each year at animal shelters. Some believe that relinquishment to a shelter, whether publicly or privately managed, is tantamount to a death sentence for a pet who otherwise could be adopted. Others aver that shelters act, in part, as economical government or privately (nonprofit) sponsored substitutes for the more costly euthanasia services provided by veterinary hospitals. These perceptions beg the question of precisely what constitutes pet surplus and, given its definition, what is its magnitude.

An uncontroversial assessment of pet surplus remains elusive among interested segments of society. Some view the problem of euthanasia performed at animal shelters not as a problem of an overabundance of unwanted animals but, instead, as an underavailability of homes (i.e., when residential regulations or leases prohibit pet ownership). An opposing viewpoint holds that any euthanasia at a shelter remains unacceptable in modern American society; indeed, some shelters have specifically adopted a "no-kill" policy for adoptable animals as a condition of their mission. One challenge, from a sociological as well as a scientific perspective, is to understand how pet surplus occurs without engendering widespread disagreement about what it is. Some endeavors on a national scale to better understand the causes of pet relinquishment as a symptom of pet surplus have recently been published. Specific reasons for relinquishment that have been studied include behavioral problems (Salman et al., 2000), changing residences (New et al., 1999), and health and personal issues of owners (Scarlett, Salman, New, \& Kass, 1999). However, these studies focused on animals primarily relinquished for adoption.

The purpose of this article was to develop a better understanding of the kinds of pets people relinquish for euthanasia compared to those relinquished for adoption and to relate the number of pets falling into the former category to the overall number of pets relinquished to shelters. We furthermore compare owner characteristics between those relinquishing for euthanasia versus those relinquishing for adoption. The results of this work have profound implications for the way that society views animal shelters.

\section{MATERIALS AND METHODS}

The Regional Shelter Relinquishment Survey ${ }^{1}$ was conducted between March 1995 and April 1996. Interviewers specifically trained in the practice of questioning individuals in the process of relinquishing their pets visited the shelters a minimum of twice a week and attempted to interview as many people as possi-

\footnotetext{
${ }^{1}$ Four collaborating centers (Colorado State University [CO], Cornell University [NY/NJ], University of California at Davis [CA], and University of Tennessee [TN/KY]) and 12 shelters from six states (California, Colorado, Kentucky, New Jersey, New York, and Tennessee) participated in data collection and analysis.
} 
ble during each visit. In addition, it was sometimes possible through the cooperation of shelter personnel to collect limited information about pets relinquished on days that interviewers were not at shelters. The Shelter Survey includes pet information gathered by owner interview and, when owners were not available for interview, from shelter personnel who admitted the pet. Although other published work derivative of the Shelter Survey has dealt with specific reasons for relinquishment such as moving or behavioral reasons (New et al., 1999; Scarlett et al., 1999), the subsets in this study were comprised of (a) animals relinquished to shelters specifically for euthanasia at the owner's request and (b) animals relinquished to shelters to be placed for adoption. Interviewers specifically asked owners if they were relinquishing the pet to the shelter for adoption or euthanasia. These subsets excluded dogs and cats (a) turned into the shelter by individuals incognizant of the animal's (including stray animals) condition and background, (b) presented as part of a litter, (c) relinquished for reasons of owner cruelty and legal impoundment, or (d) turned in already deceased to the shelter.

Statistical analysis was performed using BMDP and StatXact statistical software. Chi-square tests of homogeneity were used to compare the distribution of categorical variables between groups. Proportions are presented with associated 95\% confidence intervals (CIs); $95 \%$ frequency intervals (FI; the 2.5 and 97.5 percentiles) are used to describe the dispersion of actual data. We present the results separately for dogs and cats.

\section{RESULTS}

A total of 2,617 dogs and 1,693 cats from the Regional Shelter Relinquishment Survey admitted to shelters were the source population for animals in this study. Either the actual owner (69\%) or other family members (29\%) relinquished a large majority of dogs. Either the actual owner (70\%) or other family members (28\%) relinquished a similarly high proportion of cats. Rarely friends of the owner performed the relinquishment. The majority of dogs (94\%) and cats $(81 \%)$ were relinquished alone; the remainders in this study represented individual litters or were turned in accompanied by a litter.

Almost all information obtained on study animals came from personal interviews with the individuals relinquishing the pets (dogs, 77\%; cats, 79\%). Shelters provided information for the remaining animals either because owners declined to participate $(11 \%)$ or because an interviewer was unavailable at the time $(11 \%)$.

According to the individuals relinquishing pets for any reason, $74 \%$ of dogs $(1,925$ of 2,617$)$ and $80 \%$ of cats $(1,348$ of 1,693$)$ were potentially adoptable, but we did not try to validate this opinion of the relinquisher in our study. However, a consequential number of dogs (615 or $24 \%)$ and cats (282 or 17\%) were 
immediately turned in for euthanasia. As with all pets turned into shelters, owners or their families were likely to be the individuals actually going to the shelters to have their pets euthanized rather than asking friends to perform the service (for both dogs and cats the proportion was 99\%). Despite the emotional difficulty of eliciting information from distressed owners at the time of relinquishment, considerable information on dogs $(73 \%)$ and cats $(76 \%)$ was obtained through on-site interviews.

Some differences were found when comparing interviewed dog owners $(n=$ 446) to dog owners unavailable for interview $(n=86)$ and to dog owners who refused to be interviewed $(n=83)$. Among dog owners, a higher percentage of those interviewed $(59.4 \%, \mathrm{CI}=54.4 \%$ to $64.3 \%)$ cited old age as a factor for euthanasia compared to those unavailable for interview $(47.4 \%, \mathrm{CI}=35.8 \%$ to $59.2 \%)$ and those who refused to be interviewed $(53.2 \%, \mathrm{CI}=41.6 \%$ to $64.5 \%)$. A similar difference was found for those who relinquished dogs for euthanasia for reasons that included behavior $20.3 \%(\mathrm{CI}=16.4 \%$ to $24.7 \%$ ) versus $17.8 \%$ $(\mathrm{CI}=9.8 \%$ to $28.5 \%)$ among those unavailable for interview and $9.2 \%(\mathrm{CI}=$ $3.8 \%$ to $18.1 \%$ ) among those who refused an interview. Only minor differences between the three groups of owners were observed for those animals relinquished for euthanasia who were ill. Fewer differences were found between interviewed and noninterviewed cat owners, although interviewed owners $(n=$ 213) reported behavioral problems as a contributory cause to euthanasia more frequently $(23.9 \%, \mathrm{CI}=17.9 \%$ to $30.8 \%)$ than unavailable noninterviewed owners $(n=31 ; 7.4 \% ; \mathrm{CI}=0.9 \%$ to $24.3 \%)$ and owners refusing to be interviewed $(n=37 ; 15.2 \%$; $\mathrm{CI}=5.1 \%$ to $31.9 \%)$.

Table 1 shows personal characteristics of the individuals relinquishing dogs and cats specifically for euthanasia; only minor differences were noted between cat and dog relinquishers. The median age of dog relinquishers rose from 36.0 years (for all relinquishers, ranging from 18 to 90 years) to 42.0 years (relinquishers who requested euthanasia), and the corresponding median ages of cat relinquishers rose from 36.0 years (ranging from 18 to 91 years) to 45.0 years. The median duration of pet ownership among dogs was 10.9 years ( $\mathrm{FI}=0.03$ to 17.0 years), whereas among cats it was 10.0 years ( $\mathrm{FI}=0.03$ to 20.1 years). Table 2 shows the distribution of length of ownership for each species.

\section{Relinquishment for Euthanasia Versus Adoption}

Comparisons between people relinquishing dogs and cats for euthanasia versus adoption revealed a telling finding: The evidence suggests that relinquishment for euthanasia frequently coincides with a long-standing commitment to the pet. The median age of dogs relinquished for euthanasia was 10.4 years ( $\mathrm{FI}=0.3$ to 17.9 years) compared to dogs relinquished for adoption (1.2 years, FI $=0.2$ to 
TABLE 1

Characteristics of Individuals Relinquishing Cats and Dogs for Euthanasia to Animal Shelters

\begin{tabular}{|c|c|c|c|c|}
\hline \multirow[b]{2}{*}{ Characteristics } & \multicolumn{2}{|c|}{ Cat Relinquishers } & \multicolumn{2}{|c|}{ Dog Relinquishers } \\
\hline & $n$ & $\%$ & $n$ & $\%$ \\
\hline \multicolumn{5}{|l|}{ Gender } \\
\hline Female & 110 & 42.3 & 248 & 44.8 \\
\hline Male & 150 & 57.7 & 306 & 55.2 \\
\hline \multicolumn{5}{|l|}{ Years of education } \\
\hline 8 to 11 & 21 & 10.8 & 55 & 13.5 \\
\hline 12 & 70 & 36.1 & 137 & 33.5 \\
\hline 13 to 14 & 92 & 47.4 & 187 & 45.7 \\
\hline 15 to 16 & 11 & 5.7 & 30 & 7.3 \\
\hline \multicolumn{5}{|l|}{ Household income ${ }^{a}$} \\
\hline$<12,500$ & 28 & 16.4 & 66 & 17.8 \\
\hline 12,500 to 19,999 & 19 & 11.1 & 36 & 9.7 \\
\hline 20,000 to 27,499 & 17 & 9.9 & 47 & 12.7 \\
\hline 27,500 to 34,999 & 28 & 16.4 & 63 & 17.0 \\
\hline 35,000 to 44,999 & 28 & 16.4 & 68 & 18.3 \\
\hline 45,000 to 74,999 & 29 & 17.0 & 64 & 17.3 \\
\hline 75,000 to 124,999 & 19 & 11.1 & 19 & 5.1 \\
\hline 125,000 plus & 3 & 1.8 & 8 & 2.2 \\
\hline \multicolumn{5}{|l|}{ Ethnic identity } \\
\hline Hispanic/Latino & 41 & 17.2 & 93 & 17.9 \\
\hline White & 168 & 70.3 & 331 & 63.5 \\
\hline African American & 21 & 8.8 & 69 & 13.2 \\
\hline Asian American & 1 & 0.4 & 13 & 2.5 \\
\hline American Indian & 1 & 0.4 & 7 & 1.3 \\
\hline Other & 7 & 2.9 & 8 & 1.5 \\
\hline
\end{tabular}

${ }^{\mathrm{a}}$ Given in dollars.

9.6 years). The initial cost of dogs relinquished for euthanasia versus adoption was similar ( $M d n=\$ 0, \mathrm{FI}=\$ 0$ to $\$ 330$ vs. $M d n=\$ 0, \mathrm{FI}=\$ 0$ to $\$ 375$, respectively), as was the number of times an owner had taken the dog to a veterinarian in the year before relinquishment $(M d n=1.0, \mathrm{FI}=0$ to 4.5 vs. $M d n=1.0, \mathrm{FI}=0$ to 3.5 , respectively). A similar pattern was noted for cats. The median age of cats relinquished for euthanasia was 10.0 years ( $\mathrm{FI}=0.2$ to 19.7 years) compared to cats relinquished for adoption $(M d n=2.0$ years, $\mathrm{FI}=0.2$ to 9.9 years). The initial cost of cats relinquished for euthanasia versus adoption was similar $(M d n=\$ 0, \mathrm{FI}=\$ 0$ to $\$ 57$ vs. $M d n=\$ 0, \mathrm{FI}=\$ 0$ to $\$ 54$, respectively $)$, as was the number of times an owner had taken the cat to a veterinarian in the year before relinquishment $(M d n=1.0, \mathrm{FI}=0$ to 4.5 vs. $M d n=1.0, \mathrm{FI}=0$ to 2.9 , respectively). 
TABLE 2

Length of Ownership of Cats and Dogs Relinquished for Euthanasia to Animal Shelters

\begin{tabular}{|c|c|c|c|c|}
\hline \multirow[b]{2}{*}{ Time $^{a}$} & \multicolumn{2}{|c|}{ Dogs } & \multicolumn{2}{|c|}{ Cats } \\
\hline & $n$ & $\%$ & $n$ & $\%$ \\
\hline 0 to 1 & 64 & 15.6 & 24 & 12.7 \\
\hline 1 to 2 & 13 & 3.2 & 13 & 6.9 \\
\hline 2 to 4 & 21 & 5.2 & 14 & 7.4 \\
\hline 4 to 6 & 11 & 2.7 & 10 & 5.3 \\
\hline 6 to 8 & 41 & 10.0 & 16 & 8.4 \\
\hline 8 to 10 & 52 & 2.7 & 19 & 10.1 \\
\hline 10 to 12 & 46 & 11.2 & 21 & 11.1 \\
\hline 12 to 14 & 71 & 17.4 & 18 & 9.5 \\
\hline 14 to 16 & 38 & 9.3 & 16 & 8.5 \\
\hline 16 to 18 & 46 & 11.2 & 30 & 15.9 \\
\hline 18 plus & 6 & 1.5 & 8 & 4.2 \\
\hline
\end{tabular}

${ }^{\mathrm{a}}$ Given in years.

Occasionally certain differences in knowledge of pet husbandry were noted between owners relinquishing for euthanasia and adoption. Dog owners relinquishing their pets for euthanasia were more likely to agree that female dogs have biannual estrus cycles (see Table 3 ) than were dog owners relinquishing their pets for adoption $(66.9 \%, \mathrm{CI}=62.1 \%$ to $71.4 \%$ vs. $57.6 \%, \mathrm{CI}=55.0 \%$ to $60.1 \%$, respectively).

Cat owners relinquishing their pets for euthanasia were more likely to agree that dogs and cats misbehave to spite their owners $(65.8 \%, \mathrm{CI}=58.8 \%$ to $72.4 \%$ vs. $54.3 \%, \mathrm{CI}=51.2 \%$ to $57.4 \%$, respectively). A smaller percentage of cat owners relinquishing their pets for euthanasia agreed that cats have a biannual estrus cycle compared to owners relinquishing their pets for adoption $(30.7 \%, \mathrm{CI}=24.3 \%$ to $37.6 \%$ vs. $35.6 \%, \mathrm{CI}=32.7 \%$ to $38.6 \%$, respectively; see Table 4 ).

\section{Euthanasia for Geriatric and Disease Reasons}

Although individuals were asked if they were relinquishing their dogs for reasons primarily related to old age or illness, it proved understandably difficult for them to distinguish disease states from presumably disease-free problems associated with aging. Seventy-four owners cited geriatric problems but not illness as the reason for euthanasia, owners of 154 dogs cited disease but not geriatric problems as the reason for euthanasia, and 223 owners cited both as reasons for euthanasia. After including 54 additional dogs whose owners provided only partial information on questions regarding old age and illness status, 505 dogs out 
TABLE 3

Selected Knowledge of Dog Husbandry in People Relinquishing Dogs for Euthanasia and for Adoption to Animals Shelters

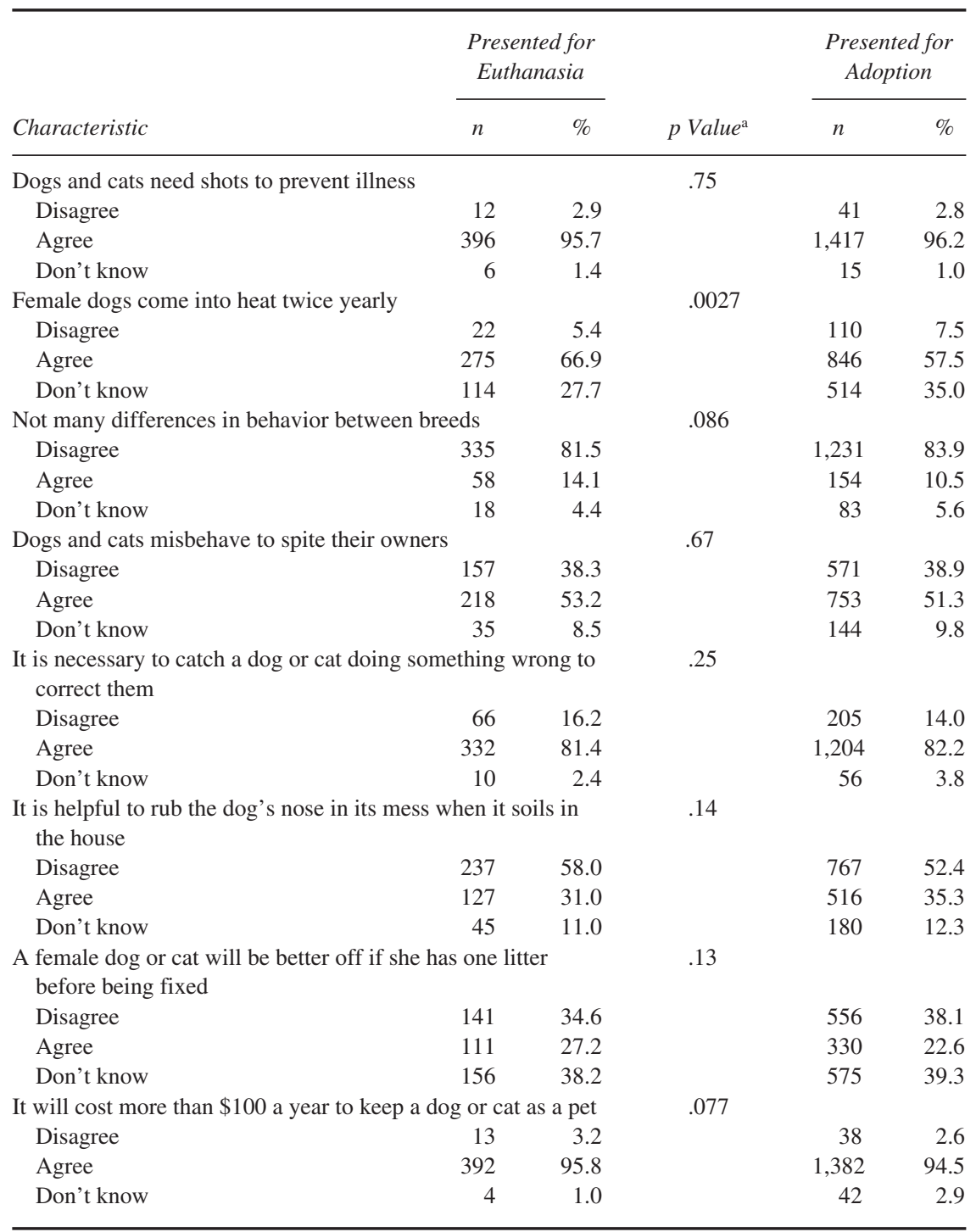

${ }^{\mathrm{a}}$ Chi-square test of homogeneity comparing distribution of responses between the two groups of relinquishers. 
TABLE 4

Selected Knowledge of Cat Husbandry in People Relinquishing Cats for Euthanasia and for Adoption to Animal Shelters

\begin{tabular}{|c|c|c|c|c|c|}
\hline \multirow[b]{2}{*}{ Characteristic } & \multicolumn{2}{|c|}{$\begin{array}{l}\text { Presented for } \\
\text { Euthanasia }\end{array}$} & \multirow[b]{2}{*}{$p$ Value $^{\mathrm{b}}$} & \multicolumn{2}{|c|}{$\begin{array}{l}\text { Presented for } \\
\text { Adoption }\end{array}$} \\
\hline & $n$ & $\%^{\mathrm{a}}$ & & $n$ & $\%^{\mathrm{a}}$ \\
\hline \multicolumn{3}{|l|}{ Dogs and cats need shots to prevent illness } & .71 & & \\
\hline Disagree & 9 & 4.5 & & 35 & 3.4 \\
\hline Agree & 187 & 94.0 & & 998 & 95.2 \\
\hline Don’t know & 3 & 1.5 & & 15 & 1.4 \\
\hline \multicolumn{3}{|l|}{ Female cats come into heat twice yearly } & .031 & & \\
\hline Disagree & 37 & 18.6 & & 247 & 23.6 \\
\hline Agree & 61 & 30.7 & & 372 & 35.6 \\
\hline Don't know & 101 & 50.8 & & 426 & 40.8 \\
\hline \multicolumn{3}{|c|}{ Cats don't mind how many other cats live in the home } & .37 & & \\
\hline Disagree & 115 & 58.6 & & 640 & 61.4 \\
\hline Agree & 55 & 28.1 & & 245 & 23.5 \\
\hline Don’t know & 26 & 13.3 & & 158 & 15.1 \\
\hline Dogs and cats misbehave to spite their owners & & & .010 & & \\
\hline Disagree & 53 & 26.6 & & 363 & 34.7 \\
\hline Agree & 131 & 65.8 & & 568 & 54.3 \\
\hline Don’t know & 15 & 7.5 & & 115 & 11.0 \\
\hline \multicolumn{3}{|c|}{$\begin{array}{l}\text { It is necessary to catch a dog or cat doing something wrong to } \\
\text { correct them }\end{array}$} & .56 & & \\
\hline Disagree & 33 & 16.6 & & 143 & 13.7 \\
\hline Agree & 155 & 77.9 & & 837 & 80.3 \\
\hline Don’t know & 11 & 5.5 & & 63 & 6.0 \\
\hline Cats pounce or scratch or bite as a form of play & & & .68 & & \\
\hline Disagree & 14 & 7.1 & & 60 & 5.7 \\
\hline Agree & 179 & 90.4 & & 964 & 92.3 \\
\hline Don’t know & 5 & 2.5 & & 21 & 2.0 \\
\hline \multicolumn{3}{|c|}{$\begin{array}{l}\text { A female dog or cat will be better off if she has one litter before } \\
\text { being fixed }\end{array}$} & .84 & & \\
\hline Disagree & 84 & 42.4 & & 453 & 43.4 \\
\hline Agree & 45 & 22.7 & & 218 & 20.9 \\
\hline Don’t know & 69 & 34.9 & & 374 & 35.8 \\
\hline \multicolumn{3}{|c|}{ It will cost more than $\$ 100$ a year to keep a dog or a cat as a pet } & .52 & & \\
\hline Disagree & 8 & 4.0 & & 47 & 4.5 \\
\hline Agree & 186 & 93.9 & & 960 & 92.0 \\
\hline Don't know & 4 & 2.0 & & 37 & 3.5 \\
\hline
\end{tabular}

${ }^{a}$ Columns may not add up to $100 \%$ due to rounding. ${ }^{b} \mathrm{Chi}$-square test of homogeneity comparing distribution of responses between the two groups of relinquishers. 
of 2,617 dogs relinquished to shelters (19\%) and out of 615 relinquished for euthanasia $(82 \%)$ were determined to have been euthanized for either or both conditions. Although house soiling was sometimes reported as a coincident undesirable behavior contributing to the decision ultimately to euthanize the pet, rarely did other reasons for relinquishment play a contributory role. The median age of dogs euthanized for these reasons was 12.0 years $(M=10.7$ years, range $=1$ month to 21 years). Half (50\%) fell between 7.9 years and 14.6 years.

A similar difficulty with cats arose when owners were asked to pinpoint the reason for having their pets euthanized. Twenty-seven cat owners listed geriatric problems as the primary reason for euthanasia, 80 owners listed illness as the primary reason for euthanasia, and 93 owners listed both. After including 44 additional cats whose owners did not respond completely to all questions on old age and illness, it was determined that a total of 224 cats out of 1,693 sheltered cats (13\%) and 282 relinquished for euthanasia (82\%) were euthanized for either or both conditions. As with dogs, house soiling was a contributory factor in the decision of some owners to decide to proceed with euthanasia; no other single behavioral reason played as important a role in the cat owners' decision. The median age of cats euthanized for these reasons was 11.9 years $(M=10.7$ years, range $=1$ month to 22 years). Half (50\%) fell between 5.8 years and 15 years.

\section{Euthanasia for Behavioral Reasons}

Of the 615 dogs specifically presented to shelters for euthanasia, 97 (16\%) were relinquished for behavioral reasons. Although dogs could be assigned more than one behavioral trait contributing to their relinquishment, the most common reasons given were those in which the dog posed a real threat to safety: aggression toward people $(n=41,42 \%)$, biting either people or other animals $(n=41,42 \%)$, and aggression toward other animals such as chasing or killing them $(n=22,30 \%)$. The more commonly occurring behavioral problems that most pet owners experience were not mentioned with nearly as much frequency as reasons for relinquishment in these 97 dogs: disobedience $(n=12,12 \%)$, excessive vocalization $(n=7,7 \%)$, escape $(n=5$, $5 \%)$, unfriendliness toward or fear of people $(n=5,5 \%)$, destructiveness inside or outside the home $(n=4,4 \%)$, house soiling $(n=4,4 \%)$, hyperactivity or jumping on people $(n=1,1 \%)$, and mistreatment by other pets $(n=1,1 \%)$. When the data were restricted to dogs whose owners were interviewed personally $(n=77)$, none of these results meaningfully changed. For example, the most common reasons given remained aggression toward people $(n=34,44 \%)$, biting either people or other animals $(n=32,42 \%)$, and aggression toward other animals such as chasing or killing them $(n=25,32 \%)$. Breed information was available for 62 of the 97 dogs (64\%) presented for euthanasia for behavior reasons; the most commonly represented breeds were German Shepherds ( $n=9)$, Cocker Spaniels $(n=8)$, Staffordshire Terriers $(n=$ 
5), Labrador Retrievers ( $n=5)$, Chihuahuas ( $n=4)$, Chow Chows $(n=4)$, and Rottweilers $(n=4)$. Of the dogs relinquished for euthanasia because of behavioral problems, only $9 \%$ were described by their owners as being ill, demonstrating that behavior alone was the reason for surrendering most of these dogs.

Of the 282 cats specifically presented to shelters for euthanasia, 50 (18\%) were specifically relinquished for behavior reasons. Like dogs, cats could be given more than one behavioral trait that led to relinquishment. Unlike dogs, house soiling was the most frequently cited behavioral complaint in cats (38\%), followed by aggression toward people (28\%), and biting either people or other animals (18\%). Less frequently mentioned behavioral problems included destructiveness inside or outside the home (14\%), fear of or unfriendliness toward owners (12\%), aggression toward other animals (8\%), and mistreatment by other pets (4\%). Of these 50 cats, $83 \%$ were described by their owners as not being ill, reinforcing the contention that behavior alone was responsible for the cats' relinquishment. When the data were restricted to cats whose owners were personally interviewed $(n=43)$, these results did not meaningfully change. For example, the most common reasons given remained house soiling (42\%), followed by aggression toward people (28\%), and biting either people or other animals (19\%).

\section{DISCUSSION}

Although it is tempting to believe that the total number of animals euthanized at animal shelters can be used as a surrogate measure of the magnitude of pet oversupply, these findings refute this belief. Approximately $24 \%$ of dogs and $17 \%$ of cats relinquished by their owners were euthanized for reasons primarily related to serious illness, old age, and to a lesser extent behavioral problems. Although some of the behavioral problems potentially could be reversed through intervention and behavioral modification, the majority of the behaviors reported as reasons for requesting euthanasia rather than adoption were serious enough to question whether such pets could successfully co-inhabit a home environment with humans or other animals. The belief that there are dogs and cats too dangerous or antisocial to be assimilated into a successful human-animal bond is not without its detractors, but with the current overabundance of pets- $76 \%$ and $83 \%$ of relinquished dogs and cats, respectively, in the opinion of the relinquishing person were adoptable - to encourage people to retain and retrain such pets at the expense of saving another animal's life (with no assurance of success) is of questionable judgment.

The exception to this may be inappropriate elimination in cats, which was the most frequent behavioral reason cited among people requesting euthanasia for cats. House soiling may have medical or behavioral causes, and owners and veterinarians must be educated to treat these effectively and thereby reduce euthanasia. 
It is encouraging to note that many of the more trivial behavioral problems did not figure prominently in peoples' decisions to have the pets immediately euthanized on surrender to shelters.

Although we were unable to collect data on the respective illnesses that contributed to the decision by the owner to have the pet euthanized, the relatively skewed age distribution toward older animals suggests that these problems may not have been medically trivial. Indeed, the median length of ownership of these dogs was 10.9 years and 10.0 years for cats, documenting in most cases a long-standing commitment to pet care. The decision to euthanize pets at veterinary hospitals typically is a balance between prognosis, quality of life, and economic reality.

Instead, it appears from our findings that many individuals use shelters as an alternative to veterinary medical hospitals. This underscores the importance of the role that local shelters play in the complex dynamic of pet ownership (including retention and relinquishment) and pet health care and decision making as well as community policy. In this circumstance, it is also arguable that such animals should not be counted toward contributing to the surplus problem.

These findings should not be taken as minimizing the magnitude of the pet surplus problem. At the very least they show that a large majority of pets are considered, at least by their former owners, to be healthy or well-adjusted enough, or both to be potentially adoptable-even accounting for the tendency of owners to overstate an animal's adoptability to diminish the likelihood of euthanasia. However, the findings also point out that shelters fulfill a critically important role in our society as alternatives to animal hospitals for euthanasia for humane reasons and, therefore, that the crude numbers of dogs and cats euthanized at shelters are not equivalent to the number of adoptable dogs and cats unnecessarily killed for lack of an available home. This presumably would force society to reconsider its perception of exactly what constitutes pet overpopulation as it is manifest at animal shelters. Our findings lead us to conclude that a sizable number of animals are relinquished to shelters because of disease, old age, or serious behavior problems. Such animals should be excluded from consideration as contributing to the definition and epidemiology of pet surplus in the United States.

\section{ACKNOWLEDGMENTS}

We acknowledge the financial support of the California Council for Companion Animal Advocates, Colorado State University; Cornell University; the University of California; and the University of Tennessee. This study was conducted under the auspices of the National Council on Pet Population Study and Policy. This research was undertaken as part of the Regional Shelter Relinquishment Survey, sponsored by the National Council on Pet Population Study and Policy (Salman et al., 1998). 
We thank the staff and directors of the participating animal shelters, the interviewers, and the participants, without whom this study would not have been possible.

\section{REFERENCES}

New, J. C., Jr., Salman, M. D., Scarlett, J. M., Kass, P. H., Vaughn, J. A., Scherr, S., \& Kelch, W. J. (1999). Moving: Characteristics of dogs and cats and those relinquishing them to 12 U.S. animal shelters. Journal of Applied Animal Welfare Science, 2, 83-96.

Salman, M. D., Hutchison, J., Ruch-Gallie, R., Kogan, L., New, J. C., Jr., Kass, P. H., \& Scarlett, J. M. (2000). Behavioral reasons for relinquishment of dogs and cats to 12 shelters (2000). Journal of Applied Animal Welfare Science, 2, 93-106.

Salman, M. D., New, J. C., Jr., Scarlett, J. M., Kass, P. H., Ruch-Gallie, R., \& Hetts, S. (1998). Human and animal factors related to the relinquishment of dogs and cats in 12 selected animal shelters in the U.S.A. Journal of Applied Animal Welfare Science, 1, 207-226.

Scarlett, J. M., Salman, M. D., New, J. G., Jr., \& Kass, P. H. (1999). Reasons for relinquishment of companion animals in U.S. animal shelters: Selected health and personal issues. Journal of Applied Animal Welfare Science, 2, 41-57. 